\title{
European men who have sex with men still at risk of HIV infection despite three decades of prevention efforts
}

K Haar (karin.haar@ecdc.europa.eu)1 ${ }^{1}$ A J Amato-Gauci'

1. European Centre for Disease Prevention and Control (ECDC), Stockholm, Sweden

Citation style for this article:

Haar K, Amato-Gauci AJ. European men who have sex with men still at risk of HIV infection despite three decades of prevention efforts. Euro Surveill.

2015;20(14):pii=21087. Available online: http://www.eurosurveillance.org/ViewArticle.aspx?Articleld=21087

Article submitted on 01 April 2015 / published on 09 April 2015

More than 30 years have passed since the first description of Pneumocystis pneumonia in homosexual men in Los Angeles in 1981 [1], as one manifestation of a supposedly Gay-Related Immune Deficiency Syndrome and since the discovery of the underlying pathogen, the human immunodeficiency virus (HIV) in 1983 [2]. Since then countries have spent considerable resources to set up surveillance systems to obtain a better overview of the HIV/AIDS epidemic and to define the most affected population groups. In Europe, EuroHIV coordinated the surveillance of AIDS and later also HIV infection between 1984 and 2007. Since 2008, the European Centre for Disease Prevention and Control (ECDC) and the World Health Organization (WHO) Regional Office for Europe have jointly coordinated HIV/AIDS surveillance in Europe and published an annual analysis of the data [3].

Men who have sex with men (MSM) have been identified as the group most at risk of HIV infection in the European Union (EU)/European Economic Association (EEA) and in the United States despite specifically targeted prevention programmes since the early years of the epidemic $[4,5]$. This can be explained by various factors. In this special issue of Eurosurveillance, published in two parts, articles from different European countries highlight a variety of factors and demonstrate how they impact the HIV/AIDS and sexually transmitted infections (STI) epidemics in MSM.

Frequent HIV testing among MSM was promoted already in the early stages of the HIV/AIDS epidemic as an important prevention measure and as having a significant benefit for the individual MSM [4,6]. Also today, the limited available evidence suggests that HIV testing uptake is higher in MSM than in other groups, such as heterosexuals, injecting drug users (IDU) and migrants in Europe [5]. Increasing numbers of newly diagnosed HIV infections in MSM could possibly be explained by increased testing, however, as seen in the trend analysis of 37,560 MSM from the United Kingdom (UK) in this issue, a true increase in incidence has taken place over the past 15 years [7]. Late presentation, defined as presenting with a CD4 count of $<350$ cells $/ \mathrm{mm}^{3}$ at date of diagnosis, was associated with increased risk of death within one year of diagnosis, particularly in MSM over 50 years in the UK [7]. Although the authors found that linkage to care had improved in recent years in the UK, culturally and linguistically appropriate services still need to be improved to enhance testing and to reduce late presentation of disease. Similarly, Diaz et al. studying determinants of late presentation (LP) with HIV infection among MSM presenting to $15 \mathrm{STI} / \mathrm{HIV}$ counselling and testing clinics in Spain, found that late presentation was particularly common among migrants from Latin America with low levels of education. The authors recommend targeted efforts to increase HIV testing uptake in those at risk groups [8]. In another Spanish study, Belza et al., showed that street-based rapid HIV testing can reduce the time of undiagnosed infections due to the high visibility and low threshold of the testing facilities, however, they recommend concentrating this type of testing in locations highly frequented by persons at higher risk [9].

Certain practices and behaviours increase the risk of MSM becoming infected with HIV or STIs. In a study investigating the diversity of practices and behaviours to prevent HIV with casual sexual partners in a large convenience sample of almost 7,000 MSM in France, Velter et al. found that many MSM persisted in engaging in high-risk practises and that seroadaptive strategies became common in the antiretroviral treatment (ART) era [10]. Seroadaptive practises are risk-reduction practises developed in order to reduce the risk of transmission, such as serosorting, where unprotected anal intercourse (UAI) is practiced with partners with same serostatus, and seropositioning, where the HIVnegative partner represents the insertive part in anal intercourse [10]. Within the Lisbon cohort, participants enrolled in an open cohort of HIV-negative MSM enrolled after testing at a community-based voluntary HIV counselling and testing centre in Lisbon. The authors followed 804 MSM for a total of 893 personyears and found that newly adopted UAI with a regular partner as well as persistent UAI with occasional partners and new syphilis infections were significantly associated with increased HIV seroconversion [11]. 
Presence of a STIs increases the risk of HIV transmission and infection [12], thus acting as another catalyst for the increase in HIV infections in MSM. In England, an analysis of the Genitourinary Medicine Clinic Activity Dataset for the years 2008 to 2013 , found that HIV-positive MSM had high rates of STI, with almost one in five of all diagnosed HIV-positive MSM having an acute STI in 2013 and increasing trends since 2009. Numbers were four times higher than in HIV-negative or undiagnosed MSM. Malek et al. conclude based on their findings that the sexual health of MSM is worsening in England [13].

More efforts are needed in certain societies where this risk group is harder to reach to better understand the epidemic and its drivers. Internet-based sampling (IBS) and recruitment can be used to gather data and improve HIV and STI testing in countries without dedicated STI services for MSM, as shown by Ruutel et al. from Estonia [14]. The authors managed to attract 301 respondents of whom $88 \%$ self-identified as MSM. Although only $26 \%$ of these went on to accept the offer of testing, this study demonstrated the feasibility of linking the Internet-based collection of behavioural data for MSM with biological sampling for HIV, hepatitis and a variety of STIs. In another study, Wirtz et al. used respondent-driven sampling (RDS) to supplement IBS to recruit 124 MSM for HIV counselling and testing (including for syphilis and human papilloma virus (HPV)) in Moscow, Russia. Taking advantage of a larger cross-sectional study where participants were invited for HIV and syphilis tests after completion of the behavioural, interviewer-administered survey, Wirtz et al. embedded a study to look into anal cytology and HPV genotyping as well as to obtain additional specimens for possible urethral, oral and rectal gonorrhoea and chlamydia infections. Again, infections with highrisk HPV types were more common in HIV-positive MSM and were strongly associated with behavioural risk and low healthcare access [15].

A systematic literature review by Strömdahl et al. [16] looked into the latest available evidence for various interventions aimed at preventing HIV and STIs in MSM in Europe. They looked at twenty-four HIV prevention interventions and of these four interventions were assigned a Highest Attainable Standard of Evidence (HASTE) grade 1: condom use, treatment as prevention, peer-led group interventions and peer outreach within the MSM community. In all, 15 interventions were graded to be strongly, probably or possibly recom. mended. This review provided the evidence-base and, together with extensive rounds of expert opinions and consultation, formed the basis for the development of a guidance document on this subject by the European Centre for Disease Prevention and Control [17].

The clear and persisting increases in HIV infections and STIs in MSM over the last decade, despite many prevention efforts, are a cause for concern. We see the need for renewed efforts and investment in evidence-based targeted and combined prevention measures among MSM. These targeted interventions, coupled with good monitoring and evaluation of the programmes will be essential if the steady rise in HIV infections and STIs among MSM is to be reversed any time soon.

\section{Conflict of interest}

None declared.

Authors' contributions

$\mathrm{KH}$ and AJAG jointly drafted the manuscript and both approved the final version.

\section{References}

1. Centers for Disease Control (CDC). Pneumocystis pneumonia-Los Angeles. MMWR Morb Mortal Wkly Rep. 1981;30(21):250-2. PMID:6265753

2. Barré-Sinoussi F, Chermann JC, Rey F, Nugeyre MT, Chamaret $\mathrm{S}$, Gruest J, et al. Isolation of a T-lymphotropic retrovirus from a patient at risk for acquired immune deficiency syndrome (AIDS). Science. 1983;220(4599):868-71. http://dx.doi. org/10.1126/science.6189183 PMID:6189183

3. European Centre for Disease Prevention and Control (ECDC)/ World Health Organization (WHO) Regional Office for Europe. Surveillance report. HIV/AIDS surveillance in Europe 2013. Stockholm: ECDC; 2014 . Available from: http://ecdc.europa. eu/en/publications/Publications/hiv-aids-surveillance-reportEurope-2013.pdf

4. Centers for Disease Control (CDC). Prevention of acquired immune deficiency syndrome (AIDS): report of interagency recommendations. MMWR Morb Mortal Wkly Rep. 1983;32(8):101-3. PMID:6403825

5. De Cock KM, Jaffe HW, Curran JW. The evolving epidemiology of HIV/AIDS. AIDS. 2012;26(10):1205-13. http://dx.doi. org/10.1097/QAD.ob013e328354622a PMID:22706007

6. Centers for Disease Control (CDC). Additional recommendations to reduce sexual and drug abuse-related transmission of human T-lymphotropic virus type III/lymphadenopathyassociated virus. MMWR Morb Mortal Wkly Rep. 1986;35(10):152-5. PMID:3005822

7. Desai S, Croxford S, Brown AE, Mitchell H, Hughes G, Delpech V. An overview of the HIV epidemic among men who have sex with men in the United Kingdom, 1999-2013. Euro Surveill. 2015;20(14).

8. Diaz A, del Romero J, Rodriguez C, Alastrué I, Belda J, Bru FJ, et al. Effects of region of birth, educational level and age on late presentation among men who have sex with men newly diagnosed with HIV in a network of STI/HIV counselling and testing clinics in Spain. Euro Surveill. 2015;20(14).

9. Belza MJ, Hoyos J, Fernández-Balbuena S, Díaz A, Bravo MJ, de la Fuente $L$, et al. Assessment of an outreach street-based HIV rapid testing programme as a strategy to promote early diagnosis: a comparison with two surveillance systems in Spain, 2008-2011. Euro Surveill. 2015;20(14).

10. Velter A, Saboni L, Sommen C, Bernillon P, Bajos N, Semaille C. Sexual and prevention practices in men who have sex with men in the era of combination HIV prevention: results from the Presse Gays et Lesbiennes survey, France, 2011. Euro Surveill. 2015;20(14).

11. Meireles P, Lucas R, Carvalho C, Fuertes R, Brito J, Campos MJ, et al. Incident risk factors as predictors of HIV seroconversion in the Lisbon cohort of men who have sex with men: first results, 2011-2014. Euro Surveill. 2015;20(14).

12. Centers for Disease Control and Prevention (CDC). STDs and HIV - CDC Fact Sheet. Atlanta: CDC. [Accessed 1 Apr 2015]. Available from: http://www.cdc.gov/std/hiv/stdfact-std-hivdetailed.htm

13. Malek R, Mitchell H, Furegato M, Simms I, Mohammed $\mathrm{H}$, Nardone A, et al. Contribution of transmission in HIVpositive men who have sex with men to evolving epidemics of sexually transmitted infections in England: an analysis using multiple data sources, 2009-2013. Euro Surveill. 2015;20(15). Forthcoming.

14. Rüütel K, Lõhmus L, Jänes J. Internet-based recruitment system for HIV and STI screening for men who have sex with men in 
Estonia, 2013: analysis of preliminary outcomes. Euro Surveill. 2015;20(15). Forthcoming.

15. Wirtz AL, Zelaya CE, Peryshkina A, McGowan I, Cranston RD, Latkin C, et al. Anal human papillomavirus and HIV: A crosssectional study among men who have sex with men in Moscow, Russia, 2012-2013. Euro Surveill. 2015;20(15). Forthcoming.

16. Strömdahl S, Hickson F, Pharris A, Sabido M, Baral S, Thorson A. A systematic review of evidence to inform HIV prevention interventions among men who have sex with men in Europe. Euro Surveill. 2015;20(15). Forthcoming.

17. European Centre for Disease Prevention and Control (ECDC). ECDC Guidance. HIV and STI prevention among men who have sex with men. Stockholm: ECDC. 2015; Forthcoming. 